\title{
Computerised Simulation of Spark Ignition Internal Combustion Engine
}

\author{
${ }^{1}$ Kota Sridhar, ${ }^{2}$ R.B.V.Murali, ${ }^{3}$ Sk.Mohammad Younus, ${ }^{4}$ K.Mohan Lakshmi \\ ${ }^{1,2,3,4}$ Mechanical Engineering Department, KL University, Vijayawada.
}

\begin{abstract}
Improving the performance of internal combustion engines is one of the major concerns of researchers. Experimental studies are more expensive than computational studies. Also using computational techniques allows us to obtain all the required data for the cylinder, which could not be measured. In this study, solution of the two dimensional, four stroke spark ignition (SI) engine with port injection is considered. The efficiency of an SI engine depends on several complicated processes including injection, mixture preparation, and Combustion and exhaust flow.

In the Present work Turbulence flow conditions are considered. Standard $k-\epsilon$ turbulence model for fluid flow and eddy break-up model for turbulent combustion were utilized. CFD analysis has been used extensively to improve each of these processes. In this paper discuss simulates the Intake, Compression, Expansion and Exhaust process with hexane fuel combustion. In-Cylinder model for simulating reciprocating engine, General strategies for modelling valve opening, closing and Discrete phase Model (DPM) for simulating port injection.

Key- words: Internal Combustion Spark ignition engine, CFD, Hexane, Combustion, Simulation.
\end{abstract}

\section{Introduction:}

UNDERSTANDING the nature of the flows and combustion in internal combustion engines are important for improving engine performance. The flows in IC engines can be characterized by swirl, tumble and compression in the cylinder. This flow motion has a strong influence on the engine combustion process and hence on the engine emission of pollutants. Recently simulation results by Computational Fluid Dynamics codes are used in the development and optimization of new engines by car manufacturers (automotive industry).

The in-cylinder fluid motion in internal combustion engines is one of the most important factors for controlling the combustion process. Swirl and tumble are well known approaches for in-cylinder flow enhancement. Swirl and tumble are generated in the intake stroke as a result of the inlet port shape and orientations. 2-dimensional modelling became as an important tool for investigating flow and combustion in reciprocal engines. In this type of modelling, the physical processes of flow and combustion in-cylinder designed with suitable boundary conditions. There are many simulation studies in the literature about 2dimensional modelling of internal combustion engines.

\subsection{Types of Internal Combustion Engines:}

There are two main types of internal combustion engines:

1. spark ignition (SI) engines (petrol or gasoline engine) and

2. Compression ignition (CI) engines (diesel engine).

Internal combustion engines are, more popularly, known as ICE because the combustion of fuel takes place inside the engine block itself. After combustion of fuel, much heat energy is generated. This is converted into mechanical energy.

\subsection{Spark Ignition Engines:}

In SI engines, the burning of fuel occurs by a spark generated by the spark plug located in the cylinder head of the engine. Due to this fact, they are called spark ignition engines. In these engines, the fuel used is petrol or gasoline, hence SI engines are also known as petrol or gasoline engines.

The (SI) and (CI) engines are either 2-stroke or 4-stroke engines. The stroke is the distance travelled by the piston inside the cylinder in one direction. In 4-stroke engines, the crankshaft rotates two rotations to be the fuel is burnt. This means the injected fuel is burnt for every four strokes of the piston inside the cylinder and the power is produced every two rotations of the crankshaft. In 2-stroke engines, the crankshaft rotates one rotation to be the fuel is burnt. This means the injected fuel is burnt for every two strokes of piston inside the cylinder and the power is produced every one rotation of the crankshaft, so ideally the power of 2-stroke engines should be double the power of 4 -stroke engines for the same volume of engine. 


\subsection{Operation of Internal Spark Ignition Engine:}

A four-stroke engine (also known as four-cycle) is an internal combustion engine in which the piston completes four separate strokes. There are

- Intake stroke

- Compression Stroke

- Power Stroke

- Exhaust Stroke

\subsubsection{Intake stroke:}

Intake or induction stroke of the piston, the piston descends from the top of the cylinder to the bottom of the cylinder, increasing the volume of the cylinder. A mixture of fuel and air, or just air in a diesel engine, is forced by atmospheric (or greater) pressure into the cylinder through the intake port. The intake valve(s) then closes. The volume of air/fuel mixture that is drawn into the cylinder, relative to the maximum volume of the cylinder, is called the volumetric efficiency of the engine.

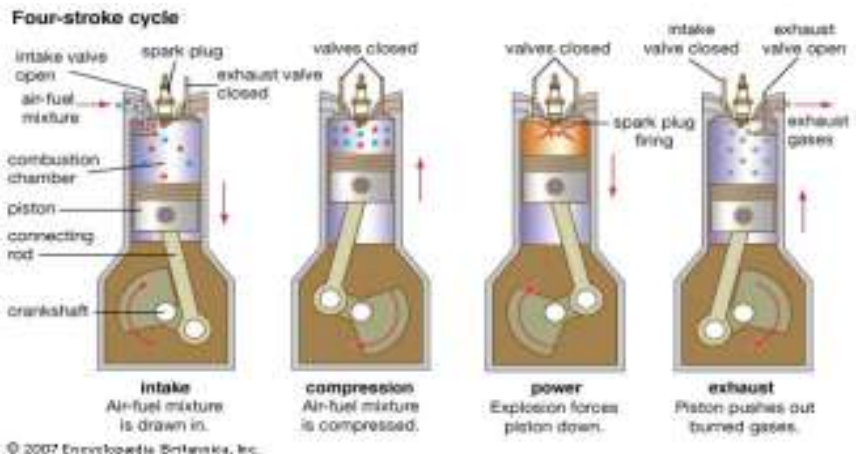

Fig: 1.4.Operation of four-stroke Spark ignition cycle

\subsubsection{Compression stroke:}

In compression stroke with both intake and exhaust valves closed, the piston returns to the top of the cylinder compressing the air or fuel-air mixture into the combustion chamber of the cylinder head. During the compression stroke the temperature of the air or fuel-air mixture rises by several hundred degrees.

\subsubsection{Power stroke:}

This is the start of the second revolution of the cycle. While the piston is close to top dead centre, the compressed air-fuel mixture in a gasoline engine is ignited, usually by a spark plug, or fuel is injected into a diesel engine, which ignites due to the heat generated in the air during the compression stroke. The resulting pressure from the combustion of the compressed fuel-air mixture forces the piston back down toward bottom dead centre.

\subsubsection{Exhaust Stroke:}

During the exhaust stroke, the piston once again returns to top dead centre while the exhaust valve is open. This action expels the spent fuel-air mixture through the exhaust valve.

\subsection{P-V diagram of 4-stroke Spark Ignition Engine:}



A: Intake Process B: Compression C:Power Stroke D:Exhaust Stroke 
1.6. Valve Time Diagram of Spark Ignition Engine:

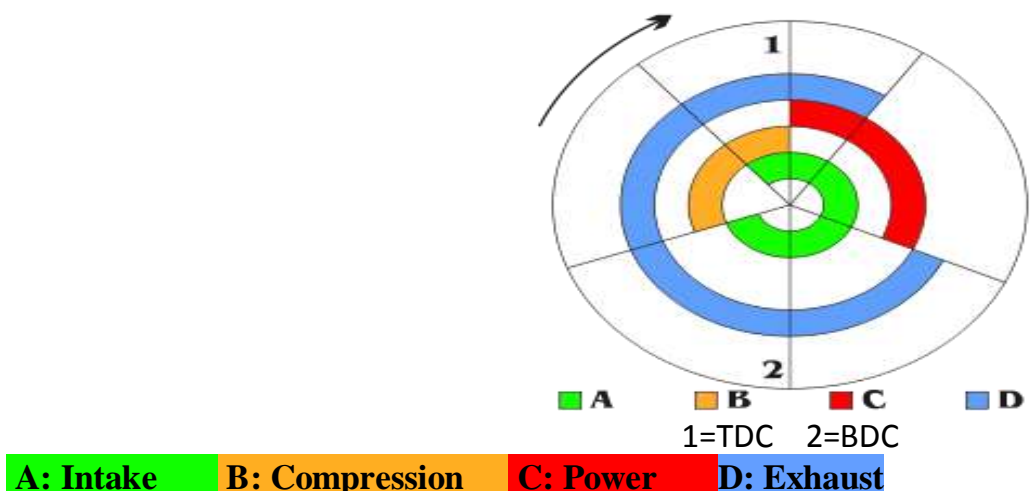

\subsection{HEXANE:}

\subsubsection{Introduction:}

Hexane is a hydrocarbon with the chemical formula $\mathrm{C}_{6} \mathrm{H}_{14}$; that is, an alkane with six carbon atoms. The term may refer to any of the five structural isomers with that formula, or to a mixture of them. ${ }^{[2]}$ In IUPAC nomenclature, however, hexane is the unbranched isomer ( $n$-hexane); the other four structures are named as methylated derivatives of pentane and butane. IUPAC also uses the term as the root of many compounds with a linear six-carbon backbone, such as 2-methylhexane $\left(\mathrm{C}_{7} \mathrm{H}_{16}\right)$, which is also called "isoheptane".

Hexanes are cheaply obtained by the refining of crude oil. The exact composition of the fraction depends largely on the source of the oil (crude or reformed) and the constraints of the refining. The industrial product (usually around $50 \%$ by weight of the straight-chain isomer) is the fraction boiling at $65-70{ }^{\circ} \mathrm{C}$. The acute toxicity of $n$-hexane is low, although it is a mild aesthetic.

The long-term toxicity of $n$-hexane in humans is well known. ${ }^{[7]}$ Extensive peripheral nervous system failure is known to occur in humans chronically exposed to levels of $n$-hexane ranging from 400 to $600 \mathrm{ppm}$, with occasional exposures up to 2,500 ppm. The initial symptoms are tingling and cramps in the arms and legs, followed by general muscular weakness. In severe cases, atrophy of the skeletal muscles is observed, along with a loss of coordination and problems of vision. Similar symptoms are observed in animal models. They are associated with a degeneration of the peripheral nervous system (and eventually the central nervous system), starting with the distal portions of the longer and wider nerve axons. The toxicity is not due to hexane itself but to one of its metabolites, hexane-2,5-dione. It is believed that this reacts with the amino group of the side chain of lysine residues in proteins, causing cross-linking and a loss of protein function.

\subsubsection{Advantages of Hexane:}

Advantages of hexane are significant constituents of gasoline. They are all colourless liquids at room temperature, with boiling points between 50 and $70{ }^{\circ} \mathrm{C}$, with gasoline-like odour. They are widely used as

- Cheap,

- Relatively safe,

- Largely unreactive, and

- Easily evaporated non-polar solvents.

\subsubsection{Uses:}

In industry, hexanes are used in the formulation of glues for shoes, leather products, and roofing. They are also used to extract cooking oils from seeds, for cleansing and degreasing a variety of items, and in textile manufacturing.

A typical laboratory use of hexanes is to extract oil and grease contaminants from water and soil for analysis. ${ }^{[3]}$ Since hexane cannot be easily deprotonated, it is used in the laboratory for reactions that involve very strong bases, such as the preparation of organolithiums, e.g. Butyllithiums are typically supplied as a hexane solution.

In many applications (especially pharmaceutical), the use of $n$-hexane is being phased out due to its long term toxicity, and often replaced by $\mathrm{n}$-heptane, which will not form the toxic metabolite hexane-2,5-dione.

\section{Problem Formulation And Description:}

The IC engine simulation is probably one of the most interesting engineering problems in the field of computational fluid dynamics. Port injection is used for client air/fuel mixing and fuel distribution in multicylinder engines. In this project, we will consider a two dimensional engine with inlet and exit valves. The 
engine is running at $2000 \mathrm{rpm}$. The intake, compression, expansion and exhaust processes are simulated with considering fuel combustion. The port injection is modelled and evaporation of fuel droplets is included. The interaction of the fuel spray with the intake valve is modelled through the wall $1 \mathrm{~m}$ modelling features available in FLUENT



2.1.Fig: Mesh of Geometry of Internal Combustion Engine

In this paper turbulent flow and combustion in an idealized homogeneous charge spark ignition engine are analyzed. It is assumed that spark plug and inlet/exhaust valves are located at the centreline of cylinder. Computations are performed for three different inlet valve angles, $0^{\circ}, 360^{\circ}$ and $720^{\circ}$, with constant engine speed $\mathrm{N}=2000 \mathrm{rpm}$, compression ratio $\mathrm{r}=9: 1$ and excess air ratio $\lambda=1.0$. Cylinder radius $\mathrm{R}=0.05 \mathrm{~m}$ and $\mathrm{r}_{\mathrm{i}}=0.04 \mathrm{~m}$ and $\mathrm{r}_{\mathrm{d}}=0.0567 \mathrm{~m}$ are chosen. Hexane $\left(\mathrm{C}_{6} \mathrm{H}_{14}\right)$ is used as a fuel.

\subsection{Design variables:}

- Piston

- Valves

- Spark Plug

- Cylinder

The In-Cylinder model is specifically used for modelling Internal Combustion Engines. It facilitates the modelling of the dynamic mesh motion of piston and valves, in terms of crank shaft angle, crank speed, piston stroke, and connecting rod length. Further, the solution is advanced in terms of crank angle, specified against crank angle step size.

The piston is currently at the top dead centre (TDC ). The TDC position is defined by $0,360,720 \ldots$ degree crank angles, while the bottom dead centre (BDC) position is defined by $180,540,900 \ldots$ degree crank angles.

A value of 720 degrees is used for four-stroke engines, while a value of 360 degrees is used for twostroke engines. This governs the periodicity associated with valve events and valve lift profiles.

\section{Engine Parameters:}

Crank Shaft Speed $=2000 \mathrm{rpm}$

Starting Crank Angle $=360^{\circ}$

Crank Period $=720^{\circ}$

Crank Angle Step Size $=0.5^{0}$

Piston Stroke $=0.09 \mathrm{~m}$

Connecting Rod Length $=0.15 \mathrm{~m} \quad$ Piston Stroke Cut-off $=0 \mathrm{~m} \quad$ Minimum valve Lift $=0 \mathrm{~m}$

The in-cylinder fluid motion in internal combustion engines is one of the most important factors controlling the combustion process. Swirl and tumble are well known approaches for in-cylinder flow enhancement. Swirl and tumble are generated in the intake stroke as a result of the inlet port shape and orientations. Multidimensional modelling became as an important tool for investigating flow and combustion in reciprocal engines. Inthis type of modelling, the physical processes of flow and combustion in-cylinder governed by Computational Fluid Methods. There are many CFD studies in the literature about Twodimensional modelling of internal combustion engines.

\section{Results And Discussions:}

In this study turbulent flow and combustion in an idealized homogeneous charge spark ignition engine are analyzed numerically. It is assumed that spark plug and inlet/exhaust valves are located at the centreline of cylinder. Computations are performed with constant engine speed $\mathrm{N}=2400 \mathrm{rpm}$, compression ratio $\mathrm{r}=9: 1$ and excess air ratio $\lambda=1.0$. Cylinder radius $\mathrm{R}=0.05 \mathrm{~m}$, stroke $\mathrm{L}=0.09 \mathrm{~m}$ and $\mathrm{r}_{\mathrm{i}}=0.04 \mathrm{~m}$ and $\mathrm{r}_{\mathrm{d}}=0.0567 \mathrm{~m}$ are chosen. Hexane $\left(\mathrm{C}_{6} \mathrm{H}_{14}\right)$ is used as a fuel. 
The Graph had shown the intake-valve, exhaust-valve with respect to Crank Angle.

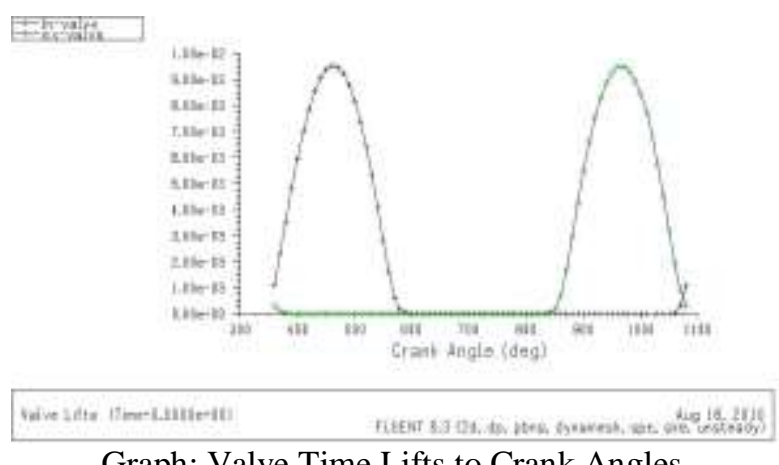

Graph: Valve Time Lifts to Crank Angles.

3.1.Simulation Result:

3.1.1.Intake Stroke:
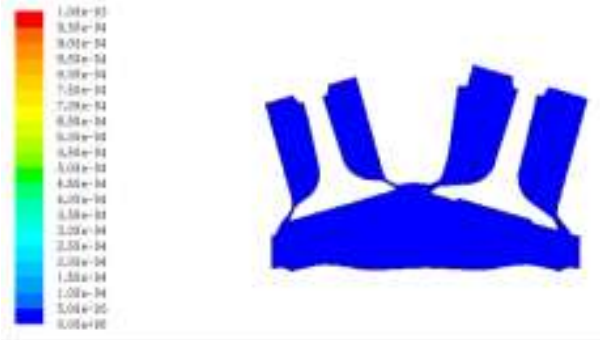

Fig: Starting Intake Stroke at Crank angle $362^{0}$

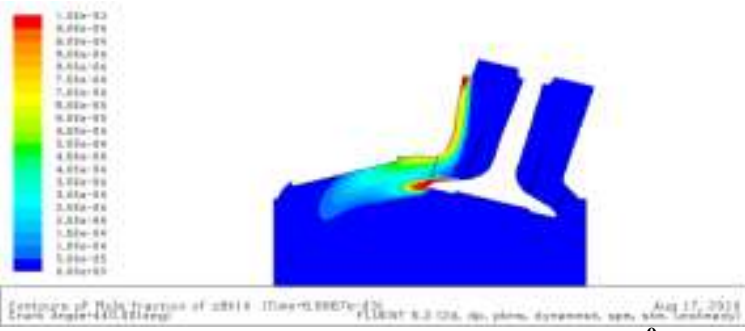

Fig:Intake Stroke at Crank angle $440^{\circ}$

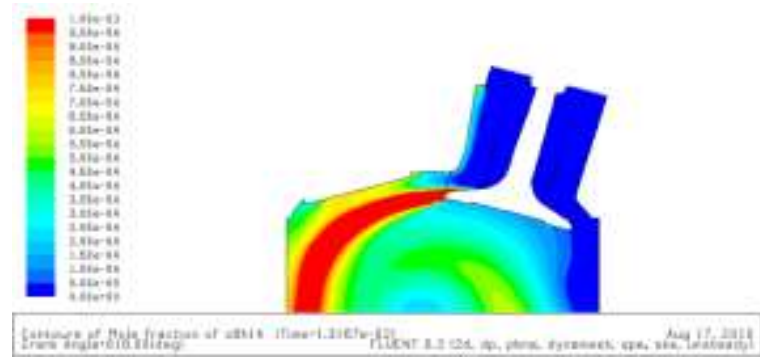

Fig:Intake Stroke at Crank Angle 518

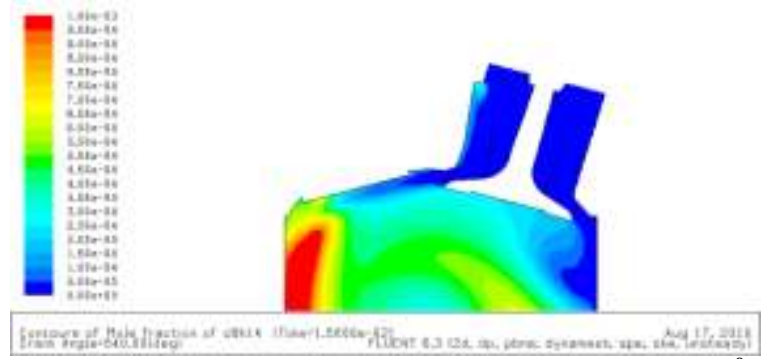

Fig:Ending of Intake Stroke at Crank Angle540 ${ }^{\circ}$ 
After Simulation the max Volume-Average static presuure 249.03122 Pa was obseved at flow time of $0.01500012 \mathrm{sec}$ at BDC and minimum volume static presure $-2058.3436 \mathrm{~Pa}$ obseved at flow time of $0.002000016 \mathrm{sec}$ at TDC simillarly Maximum Mass-Average static temperature $323.65732 \mathrm{k}$ obseved at flow time of $0.01500012 \mathrm{sec}$ at BDC, Minimum Mass-Average static temperature $317.65732 \mathrm{k}$ obseved at flow time of $0.01500012 \mathrm{sec}$ at BDC.

\subsubsection{Compression Stroke:}



Fig: Staring of Compression Stroke at Crank angle $600^{\circ}$
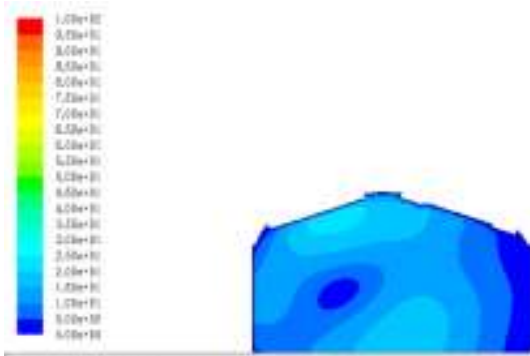

Fig: Compression Stroke at Crank angle 646 $^{\circ}$



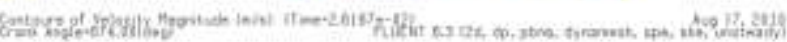

Fig: Compression Stroke at Crank angle $674^{0}$
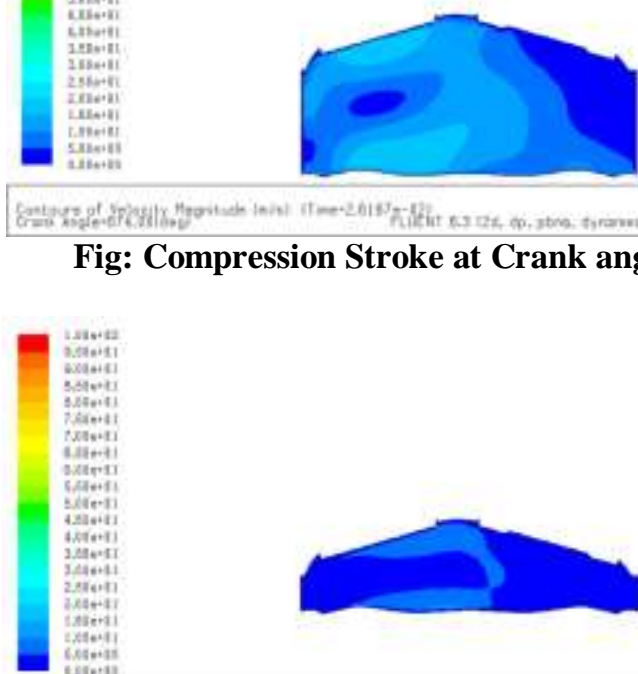

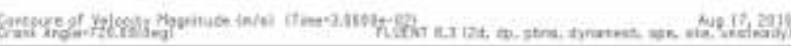

Fig: Compression Stroke at Crank angle $\mathbf{7 2 0}^{\mathbf{0}}$

After Simulation Max Volume-Average static presuure 1112305 pa was observed at flow time $0.030000241 \mathrm{sec}$ at TDC and minimum Volume-Average static presure $\quad-277.34017 \mathrm{pa}$ observed at flow time $0.002000016 \mathrm{sec}$ at BDC simillarly Maximum Mass-Average static temperature $323.65732 \mathrm{k}$ was observed at flow time $0.01500012 \mathrm{sec}$ at TDC, Minimum Mass-Average static temperature $317.65732 \mathrm{k}$ observed at flow 
time $0.002000016 \mathrm{sec}$ at BDC.

\subsubsection{Power Stroke:}



Fig: Power Stroke at Crank Angle $\mathbf{7 7 2}^{\mathbf{0}}$

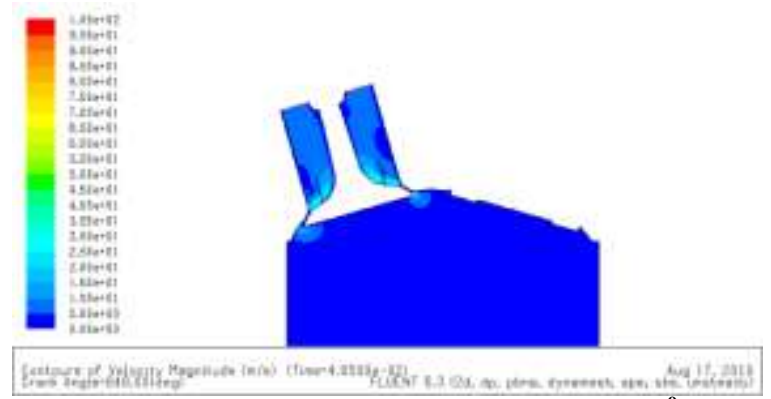

Fig: Power Stroke at Crank Angle 846

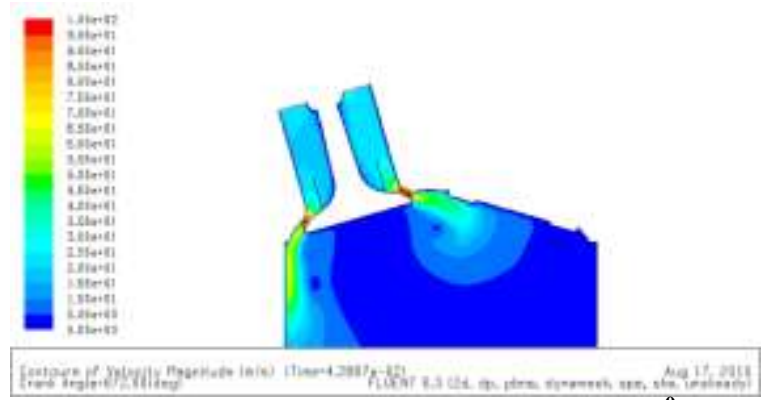

Fig: Power Stroke at Crank Angle 872 $^{0}$

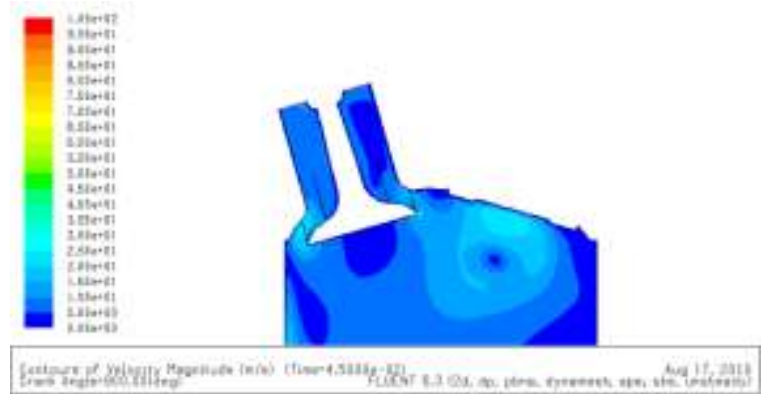

Fig: Power Stroke at Crank Angle 900

After Simulation max Volume-Average static presuure 1094149.5 pa observed at flow time 0.030166909 sec at TDC and minimum Volume-Average static presure -4887.6401pa at flow time $0.042167005 \mathrm{sec}$ observed at BDC simillarly Maximum Mass-Average static temperature $640.6545 \mathrm{k}$ observed at flow time $0.030166909 \mathrm{sec}$ obatined at TDC, Minimum Mass-Average static temperature $308.33947 \mathrm{k}$ observed at flow time $0.042167005 \mathrm{sec}$ at BDC. 


\subsubsection{Exhaust Stroke:}

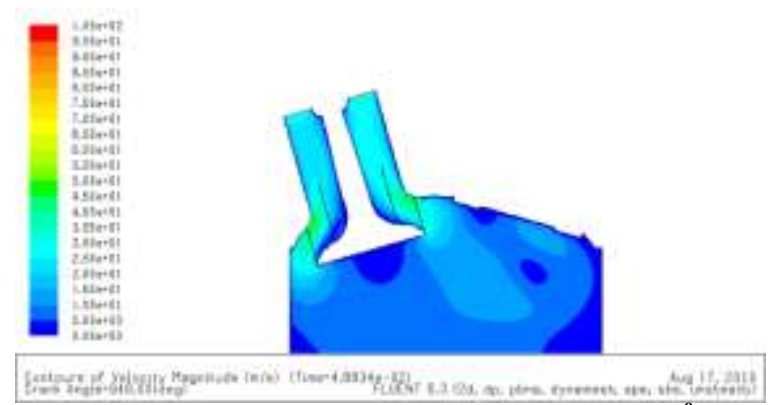

Fig: Exhaust Stroke at Crank Angle 946

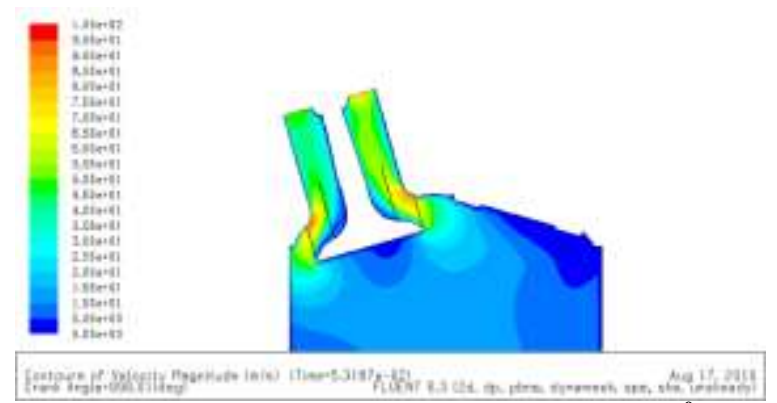

Fig: Exhaust Stroke at Crank Angle 998

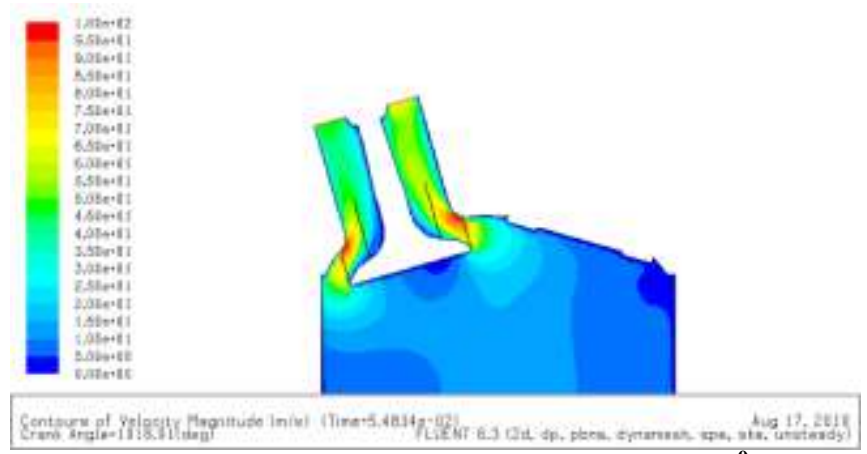

Fig: Exhaust Stroke at Crank Angle 1018

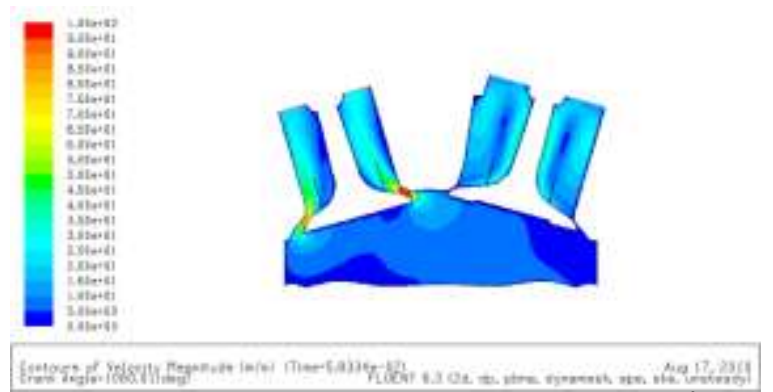

Fig: Exhaust Stroke at Crank Angle 1060

After Simulation max Volume-Average static presuure 3969.98pa observed at flow time $0.054500437 \mathrm{sec}$ at BDC and minimum we stroke Volume-Average static presure $-433.99064 \mathrm{pa}$ observed at flow time $0.060000481 \mathrm{sec}$ at TDC simillarly Maximum Mass-Average static temperature 320.52892k observed at flow time $0.054500437 \mathrm{sec}$ at TDC, Minimum Mass-Average static temperature 318.09415k observed at flow time $0.060000481 \mathrm{sec}$ at BDC. 


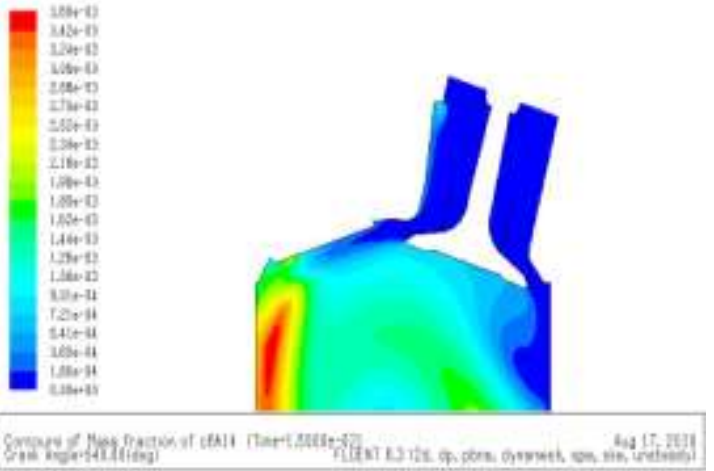

Fig: Predicted $\mathrm{C}_{6} \mathrm{H}_{14}$ Mass fraction Distribution

Display filled contours of $\mathrm{C}_{6} \mathrm{H}_{14}$ mass fraction at the 540 degree crank angle position

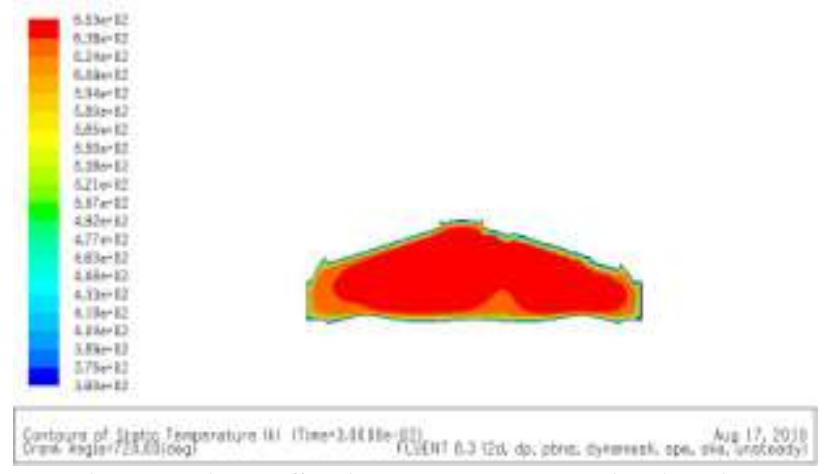

Fig: Predicted Static Temperature Distribution

Display filled contours static temperature at 720 degree crank position.

\section{Graphical Results:}

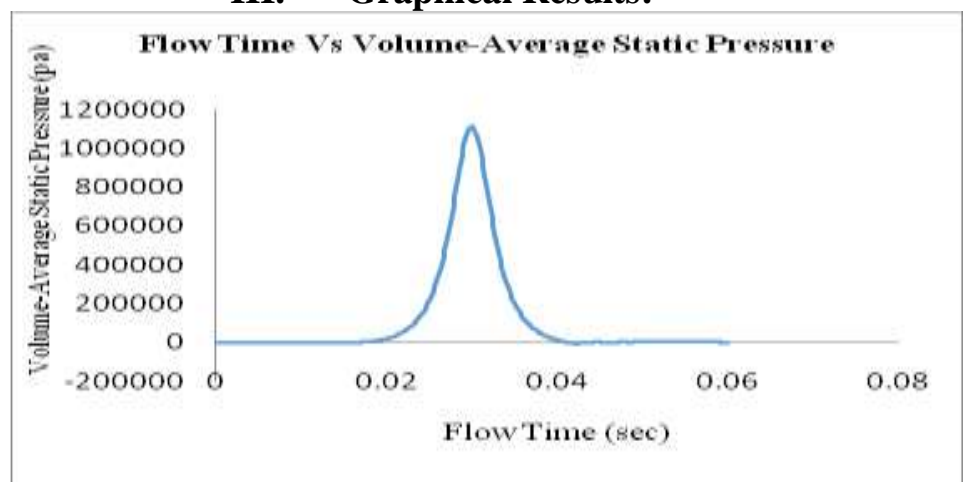

Fig: Flow Time vs Volume-Average Static pressure

After simulation process internal combustion engine spark ignation obtained differents flow times get different Volume-Average Static Pressures. The Graph observe upto some level very small amount of pressure variation that process called Intake Stroke.After Intake stroke the pressure raises gradually up to maxmium pressure that process called Compression stroke.After reachs maxmium pressure rapidly decreases that process called Power Stroke. After power stroke the pressure variation is very small amount that process is called Exhaust Stroke the graph given above. Maximum Volume-Average static pressure 1112305pa gets at flow time $0.030166909 \mathrm{sec}$ and minimum Volume-Average static pressure $-4887.6401 \mathrm{pa}$ gets at flow time $0.042167005 \mathrm{sec}$. 


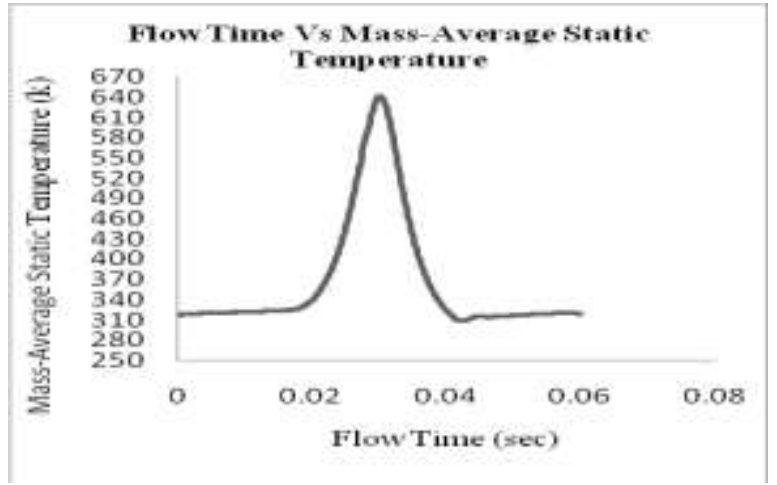

Fig:Flow time vs Mass-Average static Temperature

After simulation process internal combustion engine spark ignation obatained differents flow times get different Mass-Average Static temperatue. The Graph observe upto some process very small amount of tempreature variation that process called Intake Stroke.After Intake stroke the temperture raises gradually up to maxmium temperture that process called Compression stroke.After reachs maxmium temperture suddenly reduces the temperture that process called Power Stroke. After power stroke the temperture variation is very small amount that process is called Exhaust Stroke the graph given above. Maximum Mass-Average static temperature $641.12963 \mathrm{k}$ gets at flow time $0.030166909 \mathrm{sec}$ and minimum Mass-Average static temperature $314.24482 \mathrm{k}$ gets at flow time $0.002000016 \mathrm{sec}$.

\section{Conclusion:}

In the present work A four-stroke internal combustion spark ignition engine is simulation model. All, suction, compression, expansion and exhaust strokes are simulated. The Discrete Phase Model is used for simulating fuel injection, evaporation, and droplet boiling. The simulation model developed successfully captures the single cylinder spark ignition engine operating with Hexane as fuel. Result were noted with different crank angles at different flow time. It is found Maximum and Minimum Volume-Average static pressures, Mass-Average static Temperatures at different flow time, Predicted $\mathrm{C}_{6} \mathrm{H}_{14}$ Mass fraction Distribution and Predicted Static Temperature Distribution of Hexane Fuel. The operational range of the model is wide and computational run time is short, thus making the simulation model suitable for use with thermodynamically based cycle simulations in spark ignition engines running with ignition improver with Hexane fuel. Due to its simplicity, the model can be used for wide range of different fuels to optimize the design.

\section{References:}

[1] Benson R,S. The Thermodynamics and Gas Dynamics of Internal Combustion Engines: VoI. 1. Clarendon Press, Oxford, 1982.

[2] Stone CR. \& Etiman Y. Review of induction system design and a comparison between prediction and results from a single cylinder diesel engine. SAE paper No. 921734, 1992.

[3] Charlton SJ. Simulation program for Internal Combustion Engines. University of Bath, 1990.

[4] DYNOMATION - Four Cycle wave Action Simulator. Audie Technology Inc. and VP Engineering Inc., 1994.

[5] Williams PNT. Modeling of internal combustion engine thermo- dynamics, valve dynamics and valve flow. MSc Eng thesis, University of Stellenbosch , 2002.

[6] Van Vuuren CM. Modelling of internal combustion engine in- take and exhaust processes. MScEng thesis, University of Stellenbosch, 2001.

[7] Low SC 8. Baruah PC. A generalized computer aided de- sign package for I.C. engine manifold systems. SAE pape,r No. 810498,1991 .

[8] Fluent manual for simulation process.

[9] J. B. Heywood, Internal Combustion Engine Fundamentals. New York: McGraw-Hill, 1988.

[10] G. H. Abd Alla, "Computer simulation of a four stroke spark ignition engine” En. Convers. Mng., vol. 43, 2002, pp. 1043-1061

[11] S. H. Chan and J. Zhu, "Modelling of engine in-cylinder thermodynamics under high values of ignition retard", Int. J. Therm. Sci., vol. 40, 1999, pp. 94-103.

[12] C. R. Ferguson, Internal Combustion Engines, Applied Thermosciences. New York: John Wiley and Sons, 1986. 